\title{
Ultrasound Assisted Extraction of Oil from Soybean
}

\author{
Owais Yousuf*, Palmei Gaibimei and Anupama Singh
}

Department of Post-Harvest Process \& Food Engineering, College of Technology, G. B. Pant University of Agriculture and Technology, Pantnagar-263145, Uttarakhand, India

\author{
*Corresponding author
}

\section{A B S T R A C T}

\begin{tabular}{|l|}
\hline K e y w o r d s \\
$\begin{array}{l}\text { Soybean oil, } \\
\text { Ultrasound assisted } \\
\text { extraction, Oil } \\
\text { yield, Sonication } \\
\text { time, Power, } \\
\text { Solvent volume }\end{array}$ \\
\hline Article Info \\
\hline $\begin{array}{l}\text { Accepted: } \\
\text { 08 June } 2018 \\
\text { Available Online: } \\
\text { 10 July } 2018\end{array}$ \\
\hline
\end{tabular}

\section{Introduction}

Oils and fats are the substances that have a profound position in human life. Biochemically, oils are usually grouped together with fats as a class of composites under lipids, one of the four major groups of large polymeric biological molecules that structure living organisms; the others being proteins, polysaccharides and nucleic acids. Fats are chemically similar to oils but differ mainly in their physical state; oils are liquid at room temperature, while fats are solids (Nelson et al., 2008). Vegetable oils are the utmost significant class of biological oils and comprise those that are edible. Oils of plant origin make up the enormous popular of these as a result of their diverse and enormous number of applications in food preparation, the most notable of which are: flavor, texture, shortening, and cooking. Few animal fats such as butter and ghee also share similar functions (Gunstone2005; Gunstone and Harwood 2007). Among vegetable oils, the leading market shares belong to those obtained from oil palm, soybeans, canola (rapeseed), sunflower, peanuts and cottonseed.

Traditionally the most preferred method of oil extraction involves the usage of an organic 
solvent to selectively transfer lipids from their biological source material (Birch and Ian 2000; Wang 2004). Hexane is the industrial favorite solvent for oil extraction from soybeans. In the case of soybeans, these tedious steps have profound industrial implications; they include cleaning, dehulling, moisture-conditioning and flaking (Hammond, Johnson et al., 2005). Hence, several advanced approaches have been suggested, that could be utilized to 'assist' the solvent extraction process. Among these, two methods have had significant success; ultrasound and microwaves and ultrasound (Lee et al., 2010).

Microwave-assisted extraction (MAE) is a thermal process while ultrasound assisted solvent extraction (UASE) is a more mechanical process. Even though MAE has been proven to extract several valuable phytochemicals, the thermal character of the method makes it unsuitable for the extraction of PUFAs due to their high vulnerability to oxidation and degradation. UASE in contrast, has been successfully utilized for the extraction of oils from different biomaterials including soybeans to changing grades of success (Prabakaran and Ravindran, 2011).

Considering all the above proofs, the aim of this research is that hexane is an efficient solvent for extracting Soybean oil, and that ultrasound-assisted solvent extraction (UASE) with hexane as solvent could be used to obtain high-quality soybean oil with greater efficiency than conventional methods.

The overall objective of the research was to boost the effectiveness of oil extraction with respect to oil yield from ground soybeans. The specific objective was thus to study the consequence of process parameters like sonication power, solvent volume and sonication time on the oil yield from soybean using Ultrasound assisted extraction.

\section{Materials and Methods}

The main objective of this research work is to standardize the operating conditions for extraction of oil from soybeans and then optimize the parameters (showed in Table 2 and Table 3) on the basis of oil recovery. Materials used and procedure adopted in this research is described as:

\section{Raw Material, Chemicals and glassware}

White Soybean variety (PS-1477) was used for the extraction of Soybean oil. This variety was obtained from the Crop research Centre of G B Pant university of Agriculture and Technology. Hexane was utilized as the solvent for the extraction of soybean oil from soybean. Hexane was taken from the department lab. Glassware like beakers, conical flasks, measuring cylinders and funnels were collected from the department's store room.

\section{Experimental setup}

It consists of different equipment required to carry out experimental work which includes sonicator, hot plate Magnetic Stirrer, refrigerator, weighing balance, grinder, soxhlet apparatus etc.

\section{Experimental design}

RSM contains of a collection of statistical and mathematical methods that can be utilized to describe the relations between the independent and response variables. It has significant usage in the design, improvement and formulation of novel commodity, also in the enhancement of current product design. It only describes the result of the independent variables or in combination, on the procedures. The usage of Box-Behnken designs to prepare experimental design is seen in the current research work. Box-Behnken designs (BBD) are a class of 
rotatable or nearly rotatable second-order designs built on three-level incomplete factorial designs. Box and Behnken recommends how to choose points from the three-level factorial plan, which permits the effectual assessment of the first- and secondorder coefficients of the mathematical mode (Box and Behnken, 1960). In BoxBehnken designs (Ferreira et al., 2007) the experimental points are situated on a hyper sphere equidistant from the central point. The number of experiments $(\mathrm{N})$ required for the development of $\mathrm{BBD}$ is defined as

$\mathrm{N}=2 \mathrm{k}(\mathrm{k}-1)+\mathrm{Co}$

Where $\mathrm{k}$ is number of factors and Co is the number of central points.

For 3 factors at three levels BBD had 17 experiments with 5 experimental runs at central points, as presented in the Table 1 .

\section{Preparation of sample}

Raw soybeans were washed to eradicate any foreign material for examples and, small stones and plant leaves that might exist after harvesting, drying, transportation and storage. Washed and conditioned soybeans were ground by means of a Cyclotec mill. A stainless steel screen with a mesh dimension of $1 \mathrm{~mm}$ was utilized to attain a constant particle dimension distribution of soybean flakes. Ground soybean flakes of size $1 \mathrm{~mm}$ were then packaged in air-tight glass jar until used.

\section{Ultrasound treatment}

Ground soybean flakes (25 g) were mixed with the selected quantity of solvent $(75,100,125 \mathrm{ml})$ in a $250 \mathrm{ml}$ glass beaker. The soybean-solvent suspension was ultrasonicated for 20, 40 and 60 minutes using a $20 \mathrm{kHz}$ ultrasonic Sonicator (Electrosonic
Industries, India) with a $2.0 \mathrm{~cm}$ probe that was immersed in the suspension. Ultrasonic wave amplitude used were 60,80 and $100 \%$. Suspensions were endlessly stimulated at a continuous stirring rate of $500 \mathrm{rpm}$ by a magnetic stirrer to avert heating of suspensions under the effect of high-intensity ultrasound. After extraction, oil: solvent mixture (miscella) was filtered using Wattman filter paper 1 . The filtrate from the filtration comprises of oil and solvent. The oil was then separated from this mixture by means of a countercurrent distillation arrangement with the heating mantle as the heat source and water as the coolant. The solvent used was also recovered. Quantity of oil extracted was determined by weighing the oil obtained after solvent removal which was kept in properly washed and sterilized test tubes.

\section{Yield determination}

The yield of oil was calculated using the following formula:

Yield $(\%)=\left(\mathrm{W}_{\mathrm{e}} / \mathrm{W}_{\mathrm{t}}\right) \times 100$

Where, $\mathrm{W}_{\mathrm{e}}$ is the quantity of oil extracted from the sample $(\mathrm{g})$ and $\mathrm{W}_{\mathrm{t}}$ is the quantity of total oil in the sample $(\mathrm{g})$. $\mathrm{W}_{\mathrm{t}}$ was obtained by Soxhlet standard extraction mode.

\section{Data analysis}

The model development was done by means of response surface methodology through use of Design expert V 9.6.0.2.Complete second order model as given in Equation-1 was fitted to the data and the model adequacy was tested using $\mathrm{R}^{2}$ (coefficient of multiple determination) and fisher's F-test. The parametric effect on various responses was done through the analysis of developed models. Regarding three independent variables a second order response function has the following general form 


$$
\begin{gathered}
Y=\beta_{0}+\sum_{i=1}^{4} \beta_{i} X_{i}+\sum_{i=1}^{3} \sum_{j=i+1}^{4} \beta_{i j} X_{i} X_{j}+\sum_{i=1}^{4} \beta_{i i} X_{i}^{2} \\
\ldots \text { (3) }
\end{gathered}
$$

Where, $\beta_{0}, \beta_{\mathrm{i}}, \beta_{\mathrm{ij}}$ are constants $\mathrm{X}_{\mathrm{i}}, \mathrm{X}_{\mathrm{j}}$ are variables (coded).

Multiple regression analysis was used to examine the experimental data so as to develop response functions and obtain variable parameters optimized corresponding to best outputs. The values of model coefficients and connected statistics in relations of lack of fit and P-value were obtained through the program. The value of $P$ represents the possibility of significance. A high $\mathrm{F}$-value is an indication of the point that the model had a significant lack of fit and therefore is inadequate. A model with lower values of $\mathrm{P}$ is considered better. The models having P-value lower than 0.1 (indicating the lack of fit is unimportant at $90 \%$ confidence level) were acknowledged.

\section{Adequacy of model}

Equation is solved by means of a statistical method called technique of least square (MLS) which is a multiple regression method utilized to fit a mathematical model to a set of experiment data producing the lowest residual possible. The results of regression analysis are obtained in terms of ANOVA, regression coefficient and associated statistics, standard deviation, coefficient of determination $\left(\mathrm{R}^{2}\right)$, lack of fit, etc. These determine adequacy of predictive model and effect of independent parameters on the response (Table 5).

\section{Results and Discussion}

The current study was thus taken with the aim of studying the outcome of process factors on oil yield from soybean using Ultrasound assisted extraction and the optimization of process parameters for oil on the basis of its yield. The experimental design used in the current study was Box-Benhken design having three variables Sonicator Power, Extraction Time and Solvent Volume with three levels of each $(60,80$ and $100 \%),(20,40$ and 60 minutes) and $(75,100$ and $125 \mathrm{ml})$ respectively. Response surface methodology was utilized to improve the process parameters. A complete second order mathematical model was fitted in the response. The competence of the model was tested using coefficient of determination $\left(\mathrm{R}^{2}\right)$ and Fisher's test. The results obtained on numerous characteristics of the study are given below.

\section{Effect of independent parameters on oil yield}

Soybean oil was extracted from ground Soybean using ultrasound assisted extraction while taking hexane as the solvent. To enhance the extraction process, parameters studies were Sonicator power (60, 80 and $100 \%)$, sonication time $(20,40$ and 60 minutes), solvent volume $(75,100$ and 125 $\mathrm{ml})$. The quantity of oil obtained during extraction is showed in table. The oil yield ranged from $48 \%$ to $84 \%$ from sample amount of $25 \mathrm{~g}$ of sample over entire experimental conditions.

The experimental data was studied to observe the noteworthy consequence of numerous process variables on the oil yield. The outcomes of study of variance for oil yield are given in Table 4. F-value was used to investigate the significance of linear, quadratic and interactive terms. $F_{\text {cal }}$ value for model was superior to $\mathrm{F}_{\mathrm{tab}}$, which implies that model was significant $(\mathrm{p}<0.01)$. The outcome of independent variables on oil yield at linear level was found highly significant at $1 \%$ level of significance $\left(\mathrm{F}_{\mathrm{cal}}>\mathrm{F}_{\mathrm{tab}}\right)$, for quadratic and interactive terms it was also observed significant. 
Multiple regression analysis was performed to fit the response parameter, oil yield. The regression coefficients for the second order model polynomial equations for the linear, quadratic and interaction terms are shown in Table 5. The statistical analysis shows that the projected model was sufficient, having significant fit and with very reasonable values of $\mathrm{R}^{2}$ for drying time. The $\mathrm{R}^{2}$ value for the oil yield was $99 \%$, which implies that the model could account for $99.00 \%$ data. Closer the value of $\mathrm{R}^{2}$ to unity, the improved the empirical model fits the actual data. Insignificant value of lack of fit showed that the developed model is valid. The second order polynomial equation was developed which represents response, oil yield as functions of Sonicator Power, Solvent Volume and Extraction Time. An empirical relationship among the responses and input variables in coded form can be expressed by the following equation:

$\mathrm{Y}=70.83+12.78 \mathrm{~A}+2.51 \mathrm{~B}+1.35 \mathrm{C}+0.38 \mathrm{AB}+$ $0.55 A C+0.12 B C+0.092 A^{2}-0.92 B^{2}-0.8 C^{2}$ ... (4)

Where, $\mathrm{Y}$ is oil yield, $\mathrm{A}, \mathrm{B}$ and $\mathrm{C}$ are the coded values of Sonication Power, Solvent Volume and Sonication Time respectively.

Table.1 Experimental design table

\begin{tabular}{|c|c|c|c|c|c|c|}
\hline \multirow[t]{2}{*}{ Expt no. } & \multicolumn{3}{|c|}{ Coded levels } & \multicolumn{3}{|c|}{ Actual levels } \\
\hline & $\mathbf{A}$ & B & $\mathbf{C}$ & $\begin{array}{c}\text { Power (A) } \\
(\%)\end{array}$ & $\begin{array}{c}\text { Solvent volume }(B) \\
\text { (Hexane) } \\
(\mathrm{ml})\end{array}$ & $\begin{array}{l}\text { Sonication time } \\
\text { (C) } \\
\text { (min) }\end{array}$ \\
\hline 1 & 0 & 1 & -1 & 80 & 100 & 40 \\
\hline 2 & 0 & -1 & 1 & 100 & 100 & 60 \\
\hline 3 & -1 & -1 & 0 & 60 & 100 & 20 \\
\hline 4 & 0 & -1 & -1 & 60 & 75 & 40 \\
\hline 5 & 1 & 1 & 0 & 80 & 75 & 60 \\
\hline 6 & 0 & 0 & 0 & 80 & 125 & 20 \\
\hline 7 & 1 & -1 & 0 & 80 & 100 & 40 \\
\hline 8 & 0 & 0 & 0 & 60 & 125 & 40 \\
\hline 9 & 0 & 0 & 0 & 80 & 100 & 40 \\
\hline 10 & 1 & 0 & -1 & 100 & 75 & 40 \\
\hline 11 & 1 & 0 & 1 & 60 & 100 & 60 \\
\hline 12 & -1 & 0 & 1 & 80 & 75 & 20 \\
\hline 13 & -1 & 1 & 0 & 100 & 125 & 40 \\
\hline 14 & 0 & 0 & 0 & 80 & 100 & 40 \\
\hline 15 & -1 & 0 & -1 & 80 & 100 & 40 \\
\hline 16 & 0 & 0 & 0 & 80 & 125 & 60 \\
\hline 17 & 0 & 1 & 1 & 100 & 100 & 20 \\
\hline
\end{tabular}


Int.J.Curr.Microbiol.App.Sci (2018) 7(7): 843-852

Table2 Values of levels of independent parameters

\begin{tabular}{|c|l|c|c|c|c|}
\hline S No. & \multicolumn{1}{|c|}{ Independent parameter } & Coded value & \multicolumn{3}{|c|}{ Value of levels } \\
\cline { 3 - 6 } & & & -1 & 0 & +1 \\
\hline $\mathbf{1}$ & Power $(\%)$ & A & 60 & 80 & 100 \\
\hline $\mathbf{2}$ & Solvent volume (ml) & B & 75 & 100 & 125 \\
\hline $\mathbf{3}$ & Sonication time(mins) & C & 20 & 40 & 60 \\
\hline
\end{tabular}

Table.3 Values of constant parameters

\begin{tabular}{|c|c|c|}
\hline S No & Parameter & Value \\
\hline $\mathbf{1}$ & Sonication frequency & $20 \mathrm{~Hz}$ \\
\hline $\mathbf{2}$ & Sample particle Size & $1 \mathrm{~mm}$ \\
\hline $\mathbf{3}$ & Sample weight & $25 \mathrm{~g}$ \\
\hline
\end{tabular}

Table.4 Oil yield

\begin{tabular}{|c|c|c|c|c|c|}
\hline Std & Run & Power (\%) & Solvent volume(ml) & Time (min) & Oil Yield (\%) \\
\hline $\mathbf{5}$ & 1 & 80 & 100 & 40 & 67.6501 \\
\hline $\mathbf{1 3}$ & 2 & 100 & 100 & 60 & 84.6316 \\
\hline $\mathbf{1 1}$ & 3 & 60 & 100 & 20 & 48.6632 \\
\hline $\mathbf{8}$ & 4 & 60 & 75 & 40 & 53.7241 \\
\hline $\mathbf{2}$ & 5 & 80 & 75 & 60 & 67.4344 \\
\hline $\mathbf{9}$ & 6 & 80 & 125 & 20 & 61.1463 \\
\hline $\mathbf{1 5}$ & 7 & 80 & 100 & 40 & 68.9395 \\
\hline $\mathbf{3}$ & 8 & 60 & 125 & 40 & 57.0819 \\
\hline $\mathbf{1 0}$ & 9 & 80 & 100 & 40 & 68.9395 \\
\hline $\mathbf{1 4}$ & 10 & 100 & 75 & 40 & 77.8611 \\
\hline $\mathbf{4}$ & 11 & 60 & 100 & 60 & 58.3958 \\
\hline $\mathbf{1 7}$ & 12 & 80 & 75 & 20 & 56.1954 \\
\hline $\mathbf{6}$ & 13 & 100 & 125 & 40 & 82.7274 \\
\hline $\mathbf{1 2}$ & 14 & 80 & 100 & 40 & 68.9395 \\
\hline $\mathbf{1 6}$ & 15 & 80 & 100 & 40 & 68.9395 \\
\hline $\mathbf{1}$ & 16 & 80 & 125 & 60 & 73.3756 \\
\hline $\mathbf{7}$ & 17 & 100 & 100 & 20 & 70.5263 \\
\hline
\end{tabular}


Table.5 ANOVA table for oil yield

\begin{tabular}{|c|c|c|c|c|c|c|}
\hline \multicolumn{7}{|c|}{ Analysis of variance table [Partial sum of squares - Type III] } \\
\hline Source & $\begin{array}{c}\text { Sum of } \\
\text { Squares }\end{array}$ & $\mathbf{d f}$ & $\begin{array}{c}\text { Mean } \\
\text { Square }\end{array}$ & $\begin{array}{c}\text { F } \\
\text { Value }\end{array}$ & $\begin{array}{c}\text { p-value } \\
\text { Prob> F }\end{array}$ \\
\hline Model & 1577.37 & 9 & 175.26 & 473.45 & $<0.0001$ \\
\hline A-Power & 871.32 & 1 & 871.32 & 2353.74 & $<0.0001$ \\
\hline B-Solvent Volume & 33.69 & 1 & 33.69 & 91.00 & $<0.0001$ \\
\hline C-Time & 20.02 & 1 & 20.02 & 54.09 & 0.0002 \\
\hline AB & 0.57 & 1 & 0.57 & 1.54 & 0.2550 \\
\hline AC & 4.78 & 1 & 4.78 & 12.91 & 0.0088 \\
\hline BC & 0.25 & 1 & 0.25 & 0.66 & 0.4426 \\
\hline $\mathbf{A}^{\mathbf{2}}$ & 0.035 & 1 & 0.035 & 0.096 & 0.7662 \\
\hline $\mathbf{B}^{2}$ & 3.60 & 1 & 3.60 & 9.72 & 0.0169 \\
\hline $\mathbf{C}^{\mathbf{2}}$ & 43.63 & 1 & 43.63 & 117.86 & $<0.0001$ \\
\hline Residual & 2.59 & 7 & 0.37 & & \\
\hline Lack of Fit & 1.26 & 3 & 0.42 & 1.26 & 0.3991 \\
\hline Pure Error & 1.33 & 4 & 0.33 & & \\
\hline Cor Total & 1579.96 & 16 & & & \\
\hline
\end{tabular}

Fig.1 Effect of solvent volume (ml) and power (\%) on oil yield

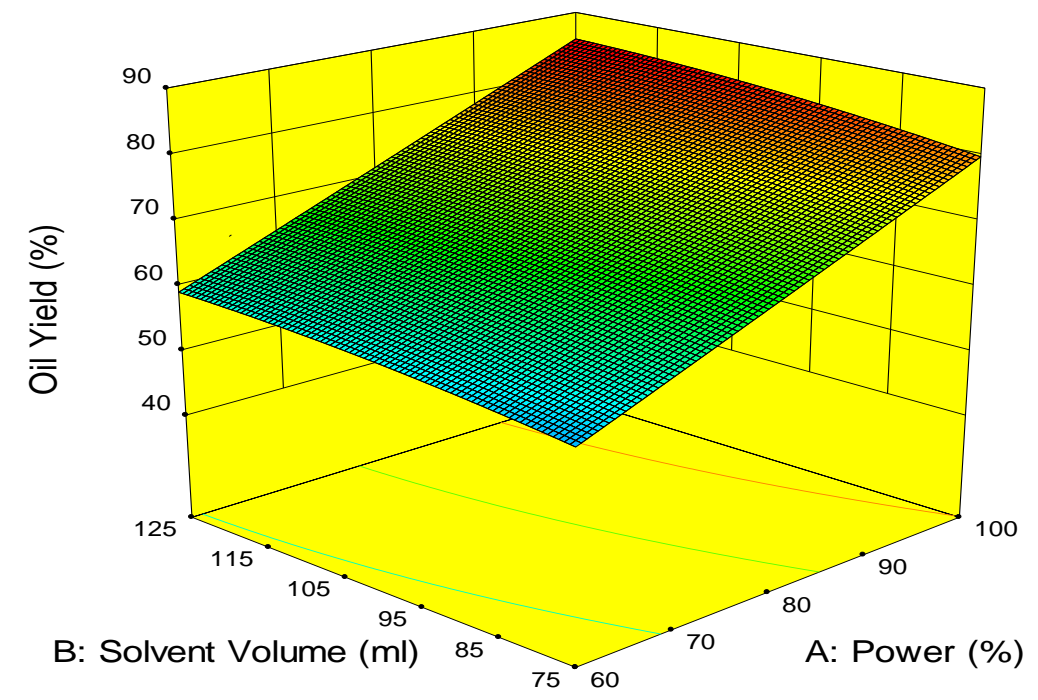


Fig.2 Effect of sonication time (min) and power (\%) on oil yield

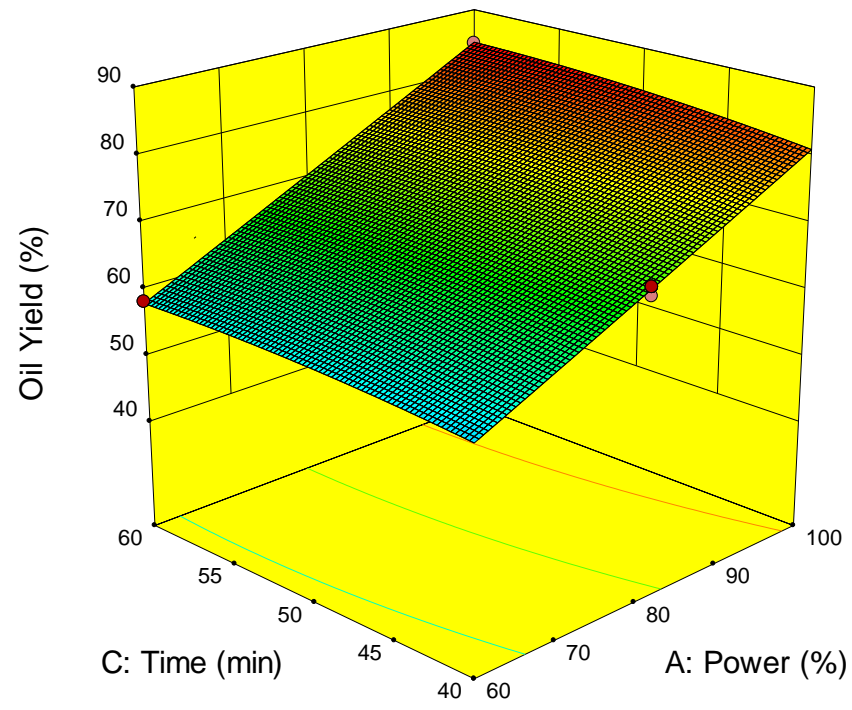

Fig.3 Effect of time (min) and solvent volume (ml) on oil yield

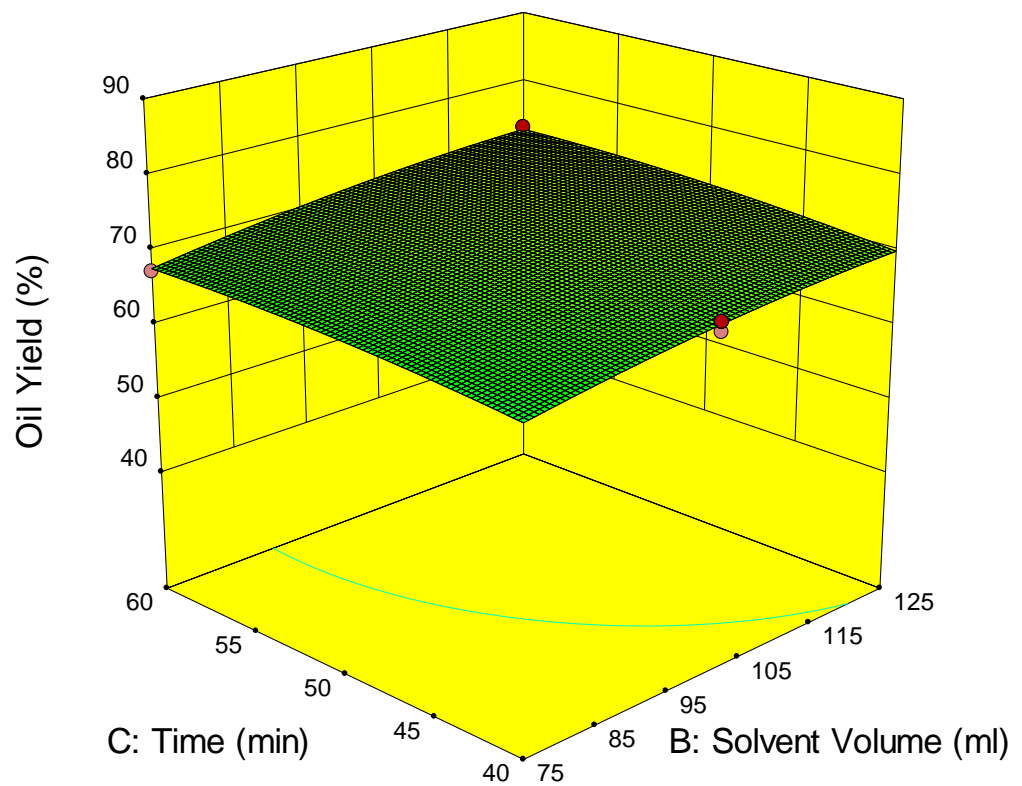




\section{Graphical analysis}

The effect of ultrasonic power on the yield of soybean oil is shown in Figure 1. It can be seen that the yield of soybean oil increases almost linearly from 48 to $84 \%$ with increasing ultrasonic power from 60 to 100 $\%$. Since the temperature and pressure were extremely great inside the bubbles and the breakdown of bubbles followed over very petite time, the violent shock wave and highspeed jet were produced which could boost the permeation of the solvent into the cell tissues and speed up the intracellular product discharge into the solvent by distracting the cell walls. Figure 2 shows the effect of experimental duration for extraction on the yield of soybean oil. It was also observed that the yield of oil increases from 48 to $84 \%$ with the upsurge in extraction time from 20 to 60 minutes. This process shows that the consequence of ultrasound is more effective at 60 minutes. It may be that ultrasonic wave possibly will disrupt the cell walls, so greater interaction region between solvent and material was generated and additional oil was released.

As shown in Figure 3, the solvent volume had significant result on the yield of soybean oil. The yield of oil extracted was found to upsurge with the rise in solvent volume from $75 \mathrm{ml}$ to $125 \mathrm{ml}$. The bigger liquid (solvent) to solid ratio signifies a larger concentration difference which aids mass transfer.

In conclusion, the use of ultrasound for soybean oil extraction showed a progressive consequence on the oil yield. The subsequent inferences were drawn from this research:

- Ultrasound had a noteworthy effect on soybean oil extraction.

- Sonication power intensity level affected the final soybean oil yield.

- Application of ultrasound increased oil yield irrespective of soybean variety.

- The selection of solvent influenced the proficiency of the ultrasound to improve yield.

- Application of ultrasound-assistance in oil extraction had a insignificant effect on oil quality, i.e., a high oil quality was still obtained.

- Choosing an ideal combination of treatment time and amplitude resulted in high oil yields.

The results obtained in this research have important implications for future usage in the soybean oil industry. This study revealed that ultrasound has the potential to be used in oil extraction method to improve efficiency and lower the processing cost. Hexane in amalgamation with other solvents can potentially be applied in soybean oil extraction because of its excellent oil extraction performance: less cost and improved safety features. Future studies will concentrate on finding the optimum combination of process parameters (ultrasound intensity, temperature, solvent, etc.) that can boost the effectiveness of oil extraction.

\section{Acknowledgement}

We are highly obliged to our fellow researchers and faculty members for their assistance and gratitude from the Department of Post-Harvest Process and Food engineering, GBPUAT, Pantnagar, India.

\section{References}

Birch, E. J. and D. W. Ian (2000). FATS Extraction By Solvent Based Methods. Encyclopedia of Separation Science. Oxford, Academic Press: 2794-2801.

Box, G. and Behnken, D. 1960. Some new three level designs for the study of quantitative variables. Technometrics. 
2:455-475.

Ferreira, S.L.C., Bruns, R.E., Ferreira, H.S., Matos, G.D., David, J.M., Brandao, G.C., Silva, E.G.P., Portugal, L.A., Reis, P.S., Souza, A.S., Santos, W.N.L., 2007. Box-Behnken design: An alternative for the optimization of analytical methods, Analytica Chimica Acta 597.179-186.

Gunstone, F. D. (2005). Vegetable Oils. Bailey's Industrial Oil and Fat Products, John Wiley \& Sons, Inc.

Gunstone, F. D. and J. L. Harwood (2007). Occurence and characterization of oils and fats. The Lipid Handbook with CD-ROM. F. D. Gunstone, J. L. Harwood and A. J. Dijkstra. Boca Raton, CRC/Taylor \& Francis.

Hammond, E. G., L. A. Johnson, et al., (2005). Soybean Oil. Bailey's Industrial Oil and Fat Products. A. E.
Bailey and F. Shahidi, John Wiley \& Sons, Inc.

Lee, J. Y., Yoo, C., Jun, S. Y., Ahn, C. Y., and Oh, H. M. (2010).Comparison of several methods for effective lipid extraction from microalgae. Bioresource technology, 101(1), S75S77.

Nelson, D. L., Lehninger, A. L., and Cox, M. M. (2008). Lehninger principles of biochemistry. Macmillan.

Prabakaran, P. and A. D. Ravindran (2011)."A comparative study on effective cell disruption methods for lipid extraction from microalgae." Letters in Applied Microbiology 53(2): 150-154.

Wang, T. (2004). Soybean Processing. Encyclopedia of Grain Science. W. Colin. Oxford, Elsevier: 159-168.

\section{How to cite this article:}

Owais Yousuf, Palmei Gaibimei and Anupama Singh. 2018. Ultrasound Assisted Extraction of Oil from Soybean. Int.J.Curr.Microbiol.App.Sci. 7(07): 843-852.

doi: https://doi.org/10.20546/ijcmas.2018.707.103 